\title{
APPLICATION OF GPS NAVIGATION IN AGRICULTURAL AGGREGATES
}

\author{
Radko Mihajlow $^{1}$, Vladimir Demirev ${ }^{1}$ \\ 1-Technical University of Varna, Dobrudhza Technological College, 9300, 12 Dobrotitca, h.e. Dobrich, Bulgaria \\ Corresponding author contact: rmihajlow@tu-varna.bg
}

\begin{abstract}
A brief analysis has been made about the emergence of the concept of "navigation". The benefits of optimal guidance of agricultural aggregates through GPS navigation are outlined. Some of the positioning accuracy methods that are practiced in agricultural aggregates are analyzed. A poll has been conducted among users of agricultural equipment using GPS navigation. Issue and conclusions are drawn on the benefits and problems for more efficient use of GPS navigation in agriculture.
\end{abstract}

Keywords: agricultural aggregates, GPS navigation, machine guidance, positioning accuracy

\section{Introduction}

The use of space navigation in agriculture is at the heart of the concept of precision agriculture, (Srinivasan, 1997.), (José P. Molin, 2010), (Daberkow, Stan G. and William D. McBride. 1998). The term navigation has a long history and is associated primarily with sea travel, but the launching of artificial satellites on Earth, the first of which was launched by the former USSR in 1957 on October 4, marks the beginning of space navigation. The life in orbit of Earth's first artificial satellite was only three months. By the twenty-second day of its launch, its two transmitters broadcast radio signals at 20,005 and 40,002 MHz frequencies that were received by radio amateurs and scientists around the world. This allowed scientists to observe the effect of Doppler, namely that the frequency of the transmitted signal from a moving source (Artificial Earth Satellite) is higher when approaching and lower when moving away. Therefore, if the exact position of a receiver on the Earth is known, the position of the satellite can be determined and vice versa, if the position of the satellite is known, the position of the receiver can be determined. Twenty years later, this principle was used by the United States in the test satellite launched to orbit on July 14, 1974, and four years later (February 22, 1978), the first operating satellite of the global positioning system was launched. The beginning of the Global Positioning System, (GPS) was set, https://bg.wikipedia.org/wiki/.

Nowadays, GPS navigation is irreplaceable in the field of military affairs, aviation, aeronautics, land transport, tourism, agriculture, geodesy and many other areas of science and practice. The availability of state-of-the-art high-tech methods and tools has expanded the navigation activities from location and course determination (direction of movement) to gathering and processing of all kinds of information about: environment, history of events, modeling and optimization of a wide range of activities. The benefits of applying satellite navigation to an agricultural aggregate contribute to: saving fertilizers and preparations; saving time and fuel; reduced depreciation and production losses; ease of operation for operators. The total benefit may amount to $15 \%$ of the cost of cultivating a crop. http://agronet.bg/agro/otglejdane/1975-precizno-zemedelie.html, (Dayton Lambert \& J. LowenbergDeBoer, 2000), (Khanna, Madhu, Onesime Faustin Epouche and Robert Hornbaker. 1999).

Various methods for increasing the precision of farming machinery are known and practiced today, but the availability of satellite navigation combined with corrective methods and means is nowhere near an alternative as it achieves accuracy up to centimeters. 


\section{Exposition}

\subsection{Analysis of methods used to reduce errors in positioning accuracy}

Like any sophisticated technical system, GPS is influenced by different sources of errors, resulting in inaccurate results in determining the coordinates of the receiver, in this case an agricultural aggregate. Basically, the system should accurately determine the parameters needed to calculate the position, but in practice, if no corrections are introduced, the positioning error can be from a few meters to tens of meters.

The main sources of errors in the processing of GPS signals are: satellite orbit - inaccurate position of the satellites; synchronizing the time of satellites and receiver - time discrepancy detected by the satellite and receiver clocks; the passage of radiated signals through the: ionosphere, which is located 200 to $50 \mathrm{~km}$ from Earth; the stratosphere, which is located $50 \mathrm{~km}$ to $10 \mathrm{~km}$ from the Earth and the troposphere, which is located up to $10 \mathrm{~km}$ from the Earth; the impact of multiple paths from different objects on Earth; error of signal reception time and Earth rotation; the mutual location of satellites and finally the intentional mistakes of the state authorities, (Минчев, М., Здравчев, И. Г., Георгиев, И., 2005.), (Rothacher, 1999).

Various methods of precision are known and practiced in the control of machines in agriculture today. Corrective methods and tools can increase accuracy to two centimeters. There are several types of methods for getting navigation corrections, that differ in the accuracy and timing of signals. The postprocessing method provides the most accurate corrections, within millimeters, but takes a long time to collect and process the data. There are differential methods that work in real time, but the accuracy of the corrections is within a meter. The so-called Real Time Kinematic (RTK) is applied which has the highest level of real-time accuracy.

\subsection{Differential Coordinate Determination. DGPS method.}

Higher positional accuracy can be obtained if the data received from the satellites is corrected by other similar data obtained from an additional receiver located at a point with known coordinates of the Earth's base station. Thus, in real time, the differences between the measured distances and the true position of the base station are determined. These differences are called differential corrections and are valid in an area with a radius of 200 to $500 \mathrm{~km}$. Broadcasted on the radio they are accepted by an unlimited number of users who can specify their position to $1-2 \mathrm{~m}$ in real time and with data accumulation and up to $0.6-0.7 \mathrm{~m}$. The method known is as Differential Global Positioning Systems (DGPS), https://en.wikipedia.org/wiki/Differential_GPS, (Минчев М., А. Андреев. 2003).

Differential corrections are broadcasted through a communication satellite system. Such systems are called "augmentation" - enhanced GPS. They are known as the abbreviation WAAS (Wide Area Augmentation System) for North America, the Multi-functional Satellite Augmentation System (MSA) for Japan and EGNOS (European Geostationary Navigation Overlay System) for Europe. https://www.novatel.com/an-introduction-to-gnss/chapter-5-resolving-errors/real-time-kinematic-rtk/

The accuracy of the DGPS is reduced by increasing the distance to the base station. The problem may get worse if the user and the station lose mutual visibility, i.e. when they are unable to "see" the same satellites.

Additional processing in DGPS is used to obtain exact positions between unknown and known points called markers. In such cases, GPS data is typically stored in the computer's memory on the GPS receivers, and then transferred to another computer running the after-processing software. The software calculates base values simultaneously using both measured data from two or more GPS receivers. Additionally processed data allows more accurate positioning because most GPS errors affect almost any receiver, so they can be removed in the calculations.

\subsection{Real Time Kinematic" (RTK) method}

Differential data can be calculated in real time by some GPS receivers by receiving a correction signal from a separate receiver, i. e. it is a kinematic (on the move) way of navigation or a "Real Time 
Kinematic" (RTK) method. The RTK method provides real-time corrections, accurate to $1 \mathrm{~cm}$ horizontally and $2 \mathrm{~cm}$ vertically (Fig. 1), https://www.novatel.com/an-introduction-to-gnss/chapter-5-resolving-errors/real-time-kinematic-rtk/.

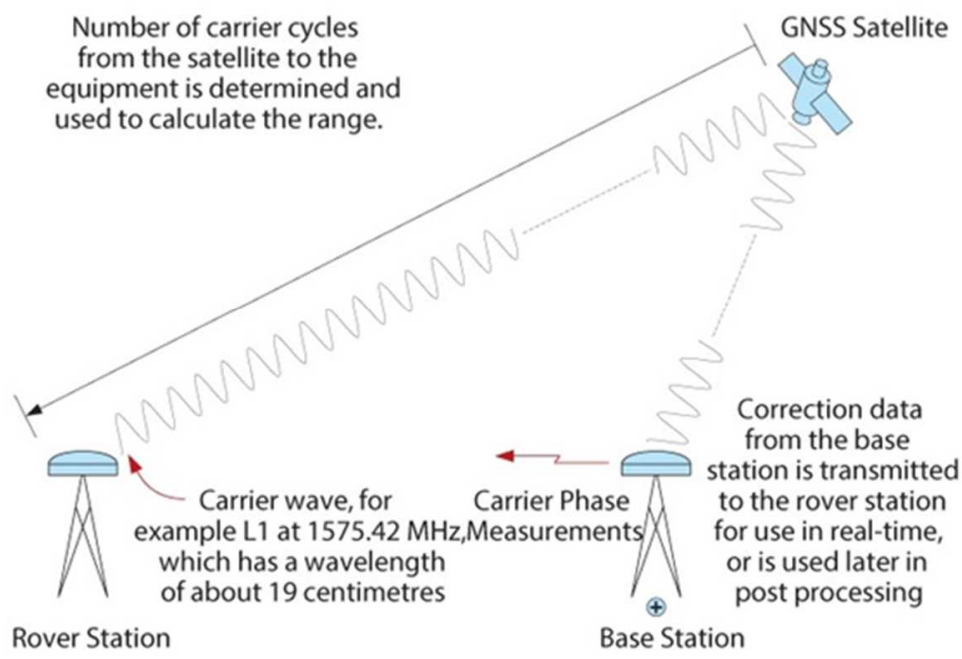

Fig. 1. Principle of operation of RTK.

RTK is used with GPS, GLONASS, GALILEO and others satellite navigation systems. The RTK measures the phase of the signal carrier wave and not the content of the information of the signal. The technology is based on a single reference station for providing real-time corrections. Regarding GPS in particular, the system is more specifically aimed at boosting the phase of the carrier frequency. The method is called Carrier-Phase Enhancement, or abbreviated CPGPS.

In the classic version, with one base station, the application of RTK is possible within a radius of up to $10 \mathrm{~km}$ around it, and if a virtual base station is created, this range can be expanded 3 to 4 times, (ChiuJung Huang and Shau-Shin Jan, 2014). In the latter case, it is necessary to operate a reference network of at least 3-4 stations at a distance of $50-70 \mathrm{~km}$ between them, and it is best to create such a network with national scope. The Virtual Reference Stations (VRS) method extends the use of RTK across the entire network area of reference stations. Operational reliability and accuracy depend on the density and capabilities of the network reference stations, http://geonet.bg/vrs-dgnss/articles/vrs-dgnss.html.

There are also Continuous Operating Reference Stations (CORS). This is a network of RTK base stations, that broadcast corrections usually via an Internet connection. Accuracy increases in the CORS network because more than one station helps to ensure proper positioning and eliminates the possibility of fake initialization of a base station.

The mobile RTK station and the moving tractor, equipped with a GPS receiver, receive signals from the same satellites, with the expectation that the disturbances between the two receivers are the same, (Fig. 2.). At a known position of the RTK, errors can be reported and a corrective signal for the position of the tractor can be made.

There are several ways to transmit a correction signal from the base station to a mobile station. The most popular way to transmit in real time is to transmit signals at a "low cost" using a radio modem, usually in the decimeter range. In most countries, certain frequencies are allocated specifically for RTK purposes. Most common ground equipment has a built-in UHF (Ultra High Frequency) band radio modem as a standard option. This allows mobile stations to calculate their relative position within millimeters, although their absolute position is accurate with the same precision as the calculated position of the base station. 


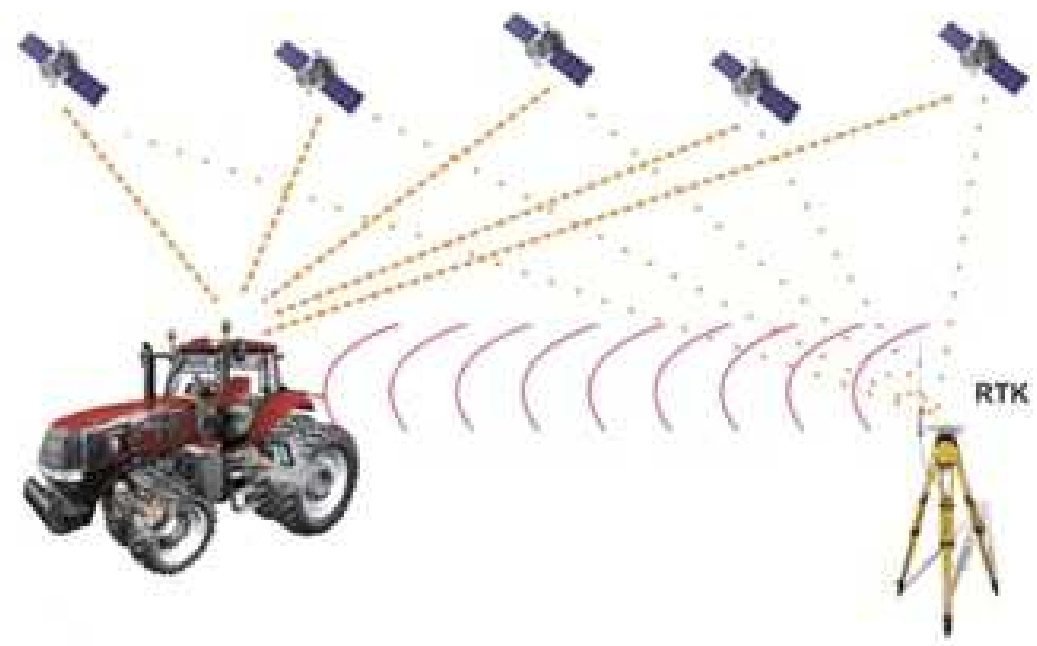

Fig. 2. The mobile RTK station.

The special satellite service provider to improve the accuracy of positioning is called OmniSTAR, http://www.omnistar.com/. OmniSTAR Correctional Signals are patented and must be paid to by the OmniSTAR Corporation to obtain permission to use. The system uses geostationary satellites in eight areas covering much of the land on every inhabited continent on Earth.

The MSV (Mobile Satellite Ventures) service is provided by the satellites: MSAT AMSC-1 and MSAT-M1. To access OmniSTAR data, the user must have an OmniSTAR-compliant receiver. OmniSTAR compatible receivers are available from a number of manufacturers of GPS devices such as Autofarm, Geneq, Hemisphere GPS, NovAtel, Topcon, Trimble, and Raven. OmniSTAR service options include both single frequency (L1) coded phase GPS solutions and technologies and dual carrier frequency (L1 / L2). Accuracy depends on satellite geometry, local conditions, receiver capabilities, and other factors, but the simple one-frequency L1 solution VBS (Virtual Base Station) gives a horizontal accuracy of less than $+/-1$ meter in more than $95 \%$ of time.

\subsection{How does OmniSTAR work?}

The OmniSTAR-VBS service works in the decimeter frequency spectrum by generating corrections to each user's GPS receivers that are optimized for the user's location. The OmniSTAR-compliant L1 GPS receiver gives both high-quality outdoor corrections and differentially geographic corrections: width / length / height values in the NMEA (National Marine Electronics Association), http://www.gpsinformation.org/dale/nmea.htm format. OmniSTAR HP and XP systems work similarly, but require OmniSTAR compatible dual-rate L1 / L2 GPS receivers.

The two - frequency L1 / L2 solution (OmniSTAR HP, OmniSTAR XP or HP / XP combined) delivers horizontal precision of less than $+/-15 \mathrm{~cm}$ and in more than $95 \%$ of the time. XP provides the use of accurate orbital and clock corrections on GPS satellites. Data is purchased from NASA.

\section{$3 \quad$ Results and analysis}

A survey of the navigation systems offered in Bulgaria is carried out and an analysis also for their application in grain-producing farms in the Dobrich region with sizes up to 2000 decares; up to 10000 decares; and over 10000 decares.

The overall impression is that navigation systems are now a standard in grain production, (Михайлов, P. et all, 2012). The opinion of all users is that they ease the work and improve the accuracy of the relevant fieldwork and field processes. In terms of efficiency, users believe that the positive effect of satellite navigation application in agricultural aggregates is on the rise. 


\subsection{Findings}

Almost all farms have accurate navigation systems for sowing.

Consumers are unaware of the way they receive corrective signals and trust external experts. In case of signal loss or delay, they are helpless and wait patiently to receive the agreed support from the supplier;

In the remote areas (up to the border with Romania), the corrective signals from remote sources are of weak and insufficient power.

It is a tendency for each agricultural company to provide itself with a RTK station or to use, for an additional fee stations owned by GPS equipment providers or to cooperate with colleagues from neighboring villages;

The best option is a complex solution: (navigation system-autopilot-service), as the agrotraders offer;

There is insufficient awareness and qualification of specific users of GPS navigation. Specialized training is needed.

Working with modern technologies requires literacy, intelligence, competence, motivation, which must be ensured not only materially but also morally.

There is inaccurate employers assessment that workers do not have anything to do if machines work on autopilot. This is absolutely untrue as the biggest autopilot transition is 10 minutes! During this time, the worker monitors the correct operation of a dozen systems on the tractor unit!

The full capabilities of GPS systems installed are not used due to incompleteness, ill-considered solutions, lack of information and lack of money.

\section{Conclusions}

Navigation systems have a place on farms over 1000 decars. In small farms and fragmented plots, efficiency is negligible or, at least unjustified because of the cost of buying and maintaining such a system;

A wide range of navigation systems is available on our market.

Men-operators are required to be literate, intelligent, competent, motivated to work.

It cannot be said that the navigation systems have invariably invaded our agriculture. Rather, they are now at their initial stage - the reasons for this are noted in the above findings.

Acknowledgements The authors wish to acknowledge Bulgarian Ministry of Education and Science and Technical University of Varna for the financial support under the Project NF4/2018.

\section{References}

Минчев, М., Здравчев, И. Г., \& Георгиев, И. (2005). Основи на приложението на GPS в геодезията. София, УАСГ.

Минчев М., А. Андреев. (2003). Върху приложението на диференциални GPS методи. Научна сесия 2002. Сборник научни трудове. част III. НВУ. Шумен 2003. 199 - 204

Михайлов, Р., Д. Томанова, Кр. Загорова, А. Боева. (2012). Прецизно земеделие, същност степен на приложение в Североизточна България, проблеми и потенциални възможности. Сборник с доклади от трети международен научен конгрес „50 години ТУ Варна”. том VII. стр. 161-166. ISBN 978-954-20-0556-8.

Rothacher, M. (1999). Basics of GPS Data Processing. Paper presented at the International Symposium on GPS at Tsukuba, Lapan. October 18-22.1999 
Srinivasan, Ancha, (1997) Handbook of precision agriculture - principles and application. The Precision Farming Guide for Agriculturists. John Deere Publishing. Moline Il. 117 p.

Huang, C. J., \& Jan, S. S. (2014). UAV Shipboard Landing with RTK, j.“. GPS World staff, 1.

José P. Molin. (2010). Precision Agriculture The theory of SSM: overview of concepts and techniques used to identify and manage within-field variability. (www.agriculturadeprecisao.org.br)

Lambert, D., \& Lowenberg-De Boer, J. (2000). Precision agriculture profitability review. Purdue Univ.

Khanna, Madhu, Onesime Faustin Epouche and Robert Hornbaker. (1999) Site-specific crop management: adoption patterns and incentives. Review of Agricultural Economics 21(2): 455-472. 1999 https://doi.org/10.2307/1349891

Daberkow, Stan G. and William D. McBride. (1998). Adoption of precision agriculture technologies by U.S. corn producers. Precision agriculture: proceedings of the fourth international conference. part B. p. 1821-1831. ASA-CSSA-SSSA. Madison WI. 1998

\section{Online sources}

Глобална_система_за_позициониране. Date of Access September 2018. Retrieved from URL https://bg.wikipe-

dia.org/wiki/\%D0\%93\%D0\%BB\%D0\%BE\%D0\%B1\%D0\%B0\%D0\%BB\%D0\%BD\%D0\%B 0_\%D1\%81\%D0\%B8\%D1\%81\%D1\%82\%D0\%B5\%D0\%BC\%D0\%B0_\%D0\%B7\%D0\%B0 _\%D0\%BF\%D0\%BE\%D0\%B7\%D0\%B8\%D1\%86\%D0\%B8\%D0\%BE\%D0\%BD\%D0\%B8 $\% \mathrm{D} 1 \% 80 \% \mathrm{D} 0 \% \mathrm{~B} 0 \% \mathrm{D} 0 \% \mathrm{BD} \% \mathrm{D} 0 \% \mathrm{~B} 5$

Differential GPS. Date of Access September 2018. Retrieved from URL https://en.wikipedia.org/wiki/Differential_GPS

An introduction to GNSS. Date of Access September 2018. Retrieved from URL https://www.novatel.com/an-introduction-to-gnss/chapter-5-resolving-errors/real-time-kinematic-rtk/

Omnistar. Date of Access September 2018. Retrieved from URL http://www.omnistar.com/

Геонет. Date of Access September 2018. Retrieved from URL http://geonet.bg/vrs-dgnss/articles/vrsdgnss.html

Прецизно земеделие - интегриран подход Retrieved from URL: https: https://www.agronet.bg/agro/1795-precizno-zemedelie.html

NMEA data. Date of Access September 2018. Retrieved from URL http://www.gpsinformation.org/dale/nmea.htm 